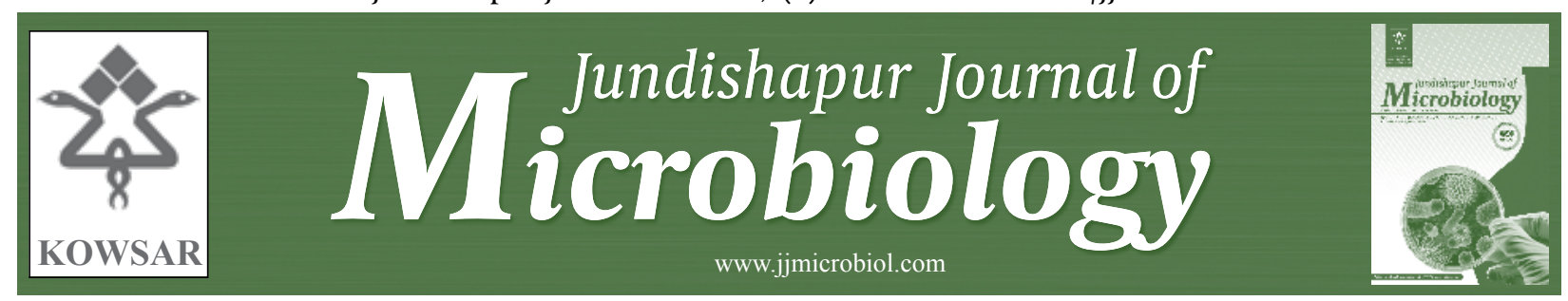

\title{
The Efficacy of Short-Term vs. Long-Term Antibiotic Therapy in Preventing Deep Infection After Orthopedic Procedures (A Prospective Observational Study)
}

\author{
Mohsen Khorrami $^{1}$, Saeid Tabatabaei ${ }^{{ }^{*}}$, Mirabbas Ahmadarabi ${ }^{2}$ \\ ${ }^{1}$ Razi Hospital, Trauma Research Center Jundishapur University of Medical Sciences, Ahvaz, IR Iran \\ ${ }^{2}$ Orthopedic Surgeon, Boroujerd, Lorestan, IR Iran
}

\begin{tabular}{l}
\hline A R T I C L E I N F O \\
\hline Article type: \\
Original Article \\
\hline Article history: \\
Received: 01 Jun 2011 \\
Revised: 03 Nov 2011 \\
Accepted: 25 Nov 2011 \\
\hline
\end{tabular}

Keywords:

Antibiotic

Short-Term

Orthopedic Procedures

\begin{abstract}
A B S T R A C T
Background: Antibiotic therapy prevents postoperative infections after orthopedic procedures, but the method and prescribed dose of this therapy are debated. Short-term prophylaxis and long-term prophylaxis are 2 accepted methods after orthopedic procedures.

Objectives: In this prospective observational study, we compared the results of shortterm and long-term prophylaxis after elective orthopedic procedures at 2 hospitals of Jundishapur University of Medical Sciences.

Patients and Methods: We divided patients who underwent uneventful orthopedic operations into 2 groups, administered short- and long-term prophylactic antibiotic therapy, respectively, and observed the patients for signs and symptoms of superficial and deep infections. We compared and analyzed the results with SPSS, considering $P$ values of less than 0.001 to indicate a significant difference.

Results: There was no significant difference regarding superficial and deep infections between short- and long-term prophylaxis groups; thus, both methods can be used for prophylaxis after elective orthopedic surgeries, effecting equal rates of success.

Conclusions: Short-term prophylaxis can be used for clean orthopedic procedures with equivalent results as long-term therapy.
\end{abstract}

Copyright $\odot 2012$ Kowsar Corp. All rights reserved.

- Implication for health policy/practice/research/medical education:

In using short-term antibiotic prophylaxis in clean orthopedic procedures we can avoid side effects and also it is more cost-effective.

Please cite this paper as:

Khorrami M; Tabatabaei S, Ahmadarabi M. The Efficacy of Short-Term vs. Long-Term Antibiotic Therapy in Preventing Deep Infection After Orthopedic Procedures (A Prospective Observational Study).Jundishapur J Microbiol.2012;5(2):427-9. DOI:10.5812/jjm.3521

\section{Background}

The use of prophylactic antibiotic therapy before the induction of anesthesia and continuing it after surgery is an accepted method of avoiding postoperative infection. $(1,2)$. Cephalosporins and other antibiotics are used widely for prophylaxis, and several reports have compared other antibiotics with cephalosporins $(3,4)$. The

${ }^{*}$ Corresponding author: Saeid Tabatabaei, Razi Hospital, Trauma Research Center, Jundishapur University of Medical Sciences, Ahvaz, IR Iran. Tel: +986113333050-1, Fax:+98-6113910857, E-mail: Saaidt1379@hotmail.com

DOI: $10.5812 / j j m .3521$

Copyright @2012 Kowsar Corp. All rights reserved. timing of postoperative antibiotic therapy is unknown, given 24-48 hours or 7-10 days after an operation (5). Although some studies recommend oral antibiotic therapy in preventing postoperative infections in revision total knee arthroplasties (6), the use of oral antibiotics after primary procedures is controversial. On the other hand, many studies do not advise routine use of antibiotics after simple soft tissue procedures, such as carpal tunnel release (7).

There are many studies that have decried the cost of long-term antibiotics and thus advocate using shortterm antibiotics (8). 


\section{Objectives}

The goal of our study was to compare the the efficacy of short-term (up to $48 \mathrm{~h}$ ) versus long-term ( $48 \mathrm{~h}$ intravenous +8 days oral) antibiotic therapy in preventing deep wound infections in orthopedic surgeries that were performed at Razi and Imam Khomeini hospitals of Jundishapur University of Medical Sciences in 858 patients over a 3-year period between April 2006 to May 2009.

\section{Patients and Methods}

In this prospective observational study, we divided the patients of the orthopedic wards of Imam Khomeini and Razi Hospitals of Jundishapur University of Medical Sciences into two groups according to a random table of numbers (for example, if the first number from the random table was 3 , we selected the third patient for short-term and the other operated patient for the longterm and continued the selection in this manner) from October 2007 to June 2008.In the first group, we begun prophylactic intravenous antibiotic therapy 30 minutes before the induction of anesthesia with $50-100 \mathrm{mg} / \mathrm{kg}$ cephalosporin (maximum $2 \mathrm{~g}$ ) and continued the dose in 4-hour intervals for 48 hours, after which we discontinued antibiotic therapy. In the second group, we continued the prophylactic antibiotic therapy by oral cephalosporin in 6-hour intervals for 10 days after discharging the patient.

The groups were identical regarding age, sex, and type of surgery. The inclusion criteria were healthy patients who were to the hospitals above who underwent open or closed reduction and internal fixation by pin, plate, and intramedullary nailing for extremity fractures or dynamic screw fixation or prosthetic application for hip fractures and patients in whom ligament reconstruction or tendon repair for upper or lower extremities was performed. The exclusion criteria were patients with preexisting diseases, such as diabetes mellitus, open fractures, history of osteomyelitis, and revision surgeries, and cases with questionable sterility during operation. After the operation we followed the patients for at least 12 weeks and recorded all problems and complications. We considered a deep infection as an infection that occurred at least 3 weeks after the primary operation and necessitated surgical debridement. We collected data from both groups and analyzed the results using SPSS and Fisher exact tests and considered a $P$ value of less than 0.001 to indicate a significant difference.

\section{Results}

There were 446 patients ( 85 females and 361 males) in the first group (short-term antibiotic therapy) and 412 patients (91 females and 321 males) in the second group (long-term therapy). The mean age of patients in first group was 33.12, year with a standard deviation of 17.08; the mean age in the second group was 37.2,year with a standard deviation of 23.28 .
In the first group, there were 28 patients (6.3\%) with forearm fractures, 204 patients with femoral fractures (45.7\%), 115 patients (25.8\%) with tibial and patella fractures, 41 patients $(9.2 \%)$ with different extensor and flexor and nerve injuries in the upper and lower limbs, 20 patients $(9.2 \%)$ with humeral fractures, 33 patients $(7.4 \%)$ with metacarpal or metatarsal fractures, and 5 patients (1.1\%) with clavicular fractures.

In the second group, there were 59 patients (14.3\%) with forearm fractures, 158 patients (38.3\%) with various femur fractures (including femoral neck, intertrochantric, subtrochantric, shaft, and distal fractures), 109 patients (26.5\%) with tibial bone (including plateau, shaft, distal tibial, bimalleolar fractures) and patellar fractures, 30 patients (7.3\%) with tendon and nerve injuries of the upper and lower limbs, 38 patients (9.2\%) with metatarsal and metacarpal fractures, and 18 patients ( $4.4 \%$ ) with clavicular fractures.

In the first group, there were 2 cases of deep infection in patients with hemiarthroplasty by Moore prosthesis versus 1 case in the second group-a 35-year-old female patient who underwent ACL reconstruction. There was no significant difference between groups regarding deep infections $(P=0.61)$.

\section{Discussion}

Regardless of the type of major orthopedic surgery, prophylactic antibiotics are necessary and a well-known method of avoiding post-operative infection (9-11). Shortterm antibiotic use has been widely reported and has become prevalent after the introduction of potent thirdgeneration cephalosporins $(8,12,13)$. The adverse effects and cost of antibiotics $(8,14)$ have been offered as reasons for short-term prophylactic antibiotic therapy, although the cost of the drugs in two methods (long- and shortterm prophylaxis) is not a significant problem in (IRIran) (142200 vs 192200 rls). We compared long-term and short-term prophlaxis in preventing deep infections in clean major orthopedic procedures.

Antibiotics are effective in preventing postoperative infections, whether short or long term (15), even in minor orthopedic surgeries that do not use an implant (12), although several studies advise against prophylactic antibiotic use in spinal surgeries without instrumentation (16) and very minor surgeries, such as carpal tunnel release, even in high-risk diabetic patients (7). In a study of 136,321 orthopedic procedures in Italian hospitals, Periti et al. (18) noted a decrease in total infection rates by approximately $50 \%$ in association with long-term ( $>24 \mathrm{~h}$ ) versus shortterm ( $<24 \mathrm{~h}$ ) antibiotic treatment (3.7 vs. 7.6\%, respectively). They recommended combination antibiotics as prophylaxis to reduce the rate of postoperative infection and concluded that the incidence of surgical site infections does not decline by extending chemoprophylaxis past the first $24 \mathrm{~h}$ after surgery, whereas it fell from $2.5 \%$ to $1.4 \%$ with combination antibiotic therapy.

Strachan (17) advocates short-term antibiotic prophy- 
laxis, even in total joint replacement surgeries. Gaetani et al. (18) also recommend short-term antibiotic prophylaxis in orthopedic and traumatologic surgeries. As demonstrated in our study of clean procedures, the rate of infection in both groups was low $0.45 \%$ in short-term and $0.24 \%$ in long-term group. In conclusion, because the rate of infection was low and essentially equal in shortterm and long-term antibiotic patients, short-term antibiotic therapy can be implemented in clean orthopedic patients instead of long-term therapy.

\section{Acknowledgements}

This study was the postgraduate thesis of Dr. Mirabbas Ahmadarabi and was supported by a grant from Jundishapur University of Medical Sciences.

\section{Financial Disclosure}

None declared.

\section{Funding/Support}

A grant from Jundishapur University of Medical Sciences.

\section{Reaferences}

1. Bratzler DW, Houck PM. Antimicrobial prophylaxis for surgery: an advisory statement from the National Surgical Infection Prevention Project. Clin Infect Dis. 2004;38 (12):1706-15.

2. Marculescu CE, Osmon DR. Antibiotic prophylaxis in orthopedic prosthetic surgery. Infect Dis Clin North Am. 2005;19 (4):931-46.

3. Mazza A. Ceftriaxone as short-term antibiotic prophylaxis in orthopedic surgery: a cost-benefit analysis involving 808 patients. J Chemother. 2000;12 (Suppl 3):29-33.

4. Van Meirhaeghe J, Verdonk R, Verschraegen G, Myny P, Paeme $\mathrm{G}$, Claessens H. Flucloxacillin compared with cefazolin in shortterm prophylaxis for clean orthopedic surgery. Arch Orthop Trau- ma Surg. 1989;108(5):308-13.

5. Nelson CL, Green TG, Porter RA, Warren RD. One day versus seven days of preventive antibiotic therapy in orthopedic surgery. Clin Orthop Relat Res. 1983 (176):258-63.

6. Zywiel MG, Johnson AJ, Stroh DA, Martin J, Marker DR, Mont MA. Prophylactic oral antibiotics reduce reinfection rates following two-stage revision total knee arthroplasty. Int Orthop. 2011;35 (1):37-42.

7. Harness NG, Inacio MC, Pfeil FF, Paxton LW. Rate of infection after carpal tunnel release surgery and effect of antibiotic prophylaxis. J Hand Surg Am. 2010;35 (2):189-96.

8. Heydemann JS, Nelson CL. Short-term preventive antibiotics. Clin Orthop Relat Res. 1986 (205):184-7.

9. de Beer J, Petruccelli D, Rotstein C, Weening B, Royston K, Winemaker M. Antibiotic prophylaxis for total joint replacement surgery: results of a survey of Canadian orthopedic surgeons. Can J Surg. 2009;52 (6):E229-34.

10. Gillespie WJ, Walenkamp GH. Antibiotic prophylaxis for surgery for proximal femoral and other closed long bone fractures. $\mathrm{Co}$ chrane Database Syst Rev. 2010 (3):CD000244.

11. Kuong EE, Ng FY, Yan CH, Fang CX, Chiu PK. Antibiotic prophylaxis after total joint replacements. Hong Kong Med J. 2009;15 (6):458-62.

12. Norlin R, Fryden A, Nilsson L, Ansehn S. Short-term cefotaxime prophylaxis reduces the failure rate in lower limb amputations. Acta Orthop Scand. 1990;61(5):460-2.

13. Wewalka G, Endler M, Kraft A. [Antibiotic concentrations in wound secretions and bone during the simultaneous administration of mezlocillin and oxacillin]. Infection. 1982;10 (Suppl 3):S213-6.

14. Yalcin AN, Erbay RH, Serin S, Atalay H, Oner O, Yalcin AD. Perioperative antibiotic prophylaxis and cost in a Turkish University Hospital. Infez Med. 2007;15 (2):99-104.

15. Mammel J, Kmet L. Perioperative antibiotic administration in orthopaedic trauma: a quality assurance project. Orthop Nurs. 2010;29 (2):77-83; quiz 4-5.

16. Kakimaru H, Kono M, Matsusaki M, Iwata A, Uchio Y. Postoperative antimicrobial prophylaxis following spinal decompression surgery: is it necessary? J Orthop Sci. 2010;15 (3):305-9.

17. Strachan CJ. Antibiotic prophylaxis in peripheral vascular and orthopaedic prosthetic surgery. J Antimicrob Chemother. 1993;31 (Suppl B):65-78.

18. Gaetani G, Carozzi S, Schiesari L, Ferrari PG, Simoncini F. [Shortterm prophylaxis in orthopedic and traumatologic surgery]. Chir Ital. 1986;38 (1):113-8. 